\title{
When to use single-inhaler triple therapy in COPD: a practical approach for primary care health care professionals
}

This article was published in the following Dove Press journal: International Journal of COPD

\section{S Gaduzo' \\ V McGovern² \\ J Roberts ${ }^{3}$ \\ JE Scullion ${ }^{4}$ \\ D Singh ${ }^{5}$}

'Stockport NHS Foundation Trust, Stockport, UK; ${ }^{2}$ Belfast Trust, Belfast, UK; ${ }^{3}$ Salford Royal NHS Foundation

Trust, Salford, UK; ${ }^{4}$ University Hospitals of Leicester, Leicester, UK; ${ }^{5}$ Medicines Evaluation Unit, University of Manchester, Manchester University NHS Foundation Hospital Trust, Manchester, UK
Correspondence: D Singh

Medicines Evaluation Unit, University of Manchester, Manchester University NHS Foundation Hospital Trust, The Langley Building, Southmoor Road, Manchester, M23 9QZ, UK

Tel +44 I6I 9464073

Email dsingh@meu.org.uk

\begin{abstract}
While single-inhaler triple therapy (SITT) devices were not available when the Global Initiative for Chronic Obstructive Lung Disease strategy and National Institute for Health and Care Excellence guidelines were developed, two devices are now available in the UK. This paper offers practical, patient-focused advice to optimize placement of SITT in the management of COPD. A survey of UK health care professionals (HCPs) identified issues around, and attitudes toward, SITT, which informed a multidisciplinary expert panel's discussions. The survey confirmed the need to clarify the place of SITT in COPD management. The panel suggested three criteria, any one of which identifies a high-risk patient where escalation to triple therapy from monotherapy or double combination treatment is appropriate: 1) at least two exacerbations treated with oral corticosteroids, antibiotics, or both in the previous year; 2) at least one severe exacerbation that required hospital admission in the previous year; 3) one exacerbation a year on a repeated basis for 2 consecutive years. Appropriate non-pharmacological management is essential for all patients and should be considered before stepping up treatment. Regular review is essential. During each review, HCPs should consider stepping treatment up or down. If patients exacerbate despite adhering to triple therapy, an individualized approach should be considered if the inhaled corticosteroid (ICS) confers benefit or causes side effects. In this situation, the blood eosinophil count could aid decision making. ICSs should be continued when the history suggests that asthma overlaps with COPD. Training, counseling, and education should be individualized. HCPs should consider referral: 1) when there is limited response to treatment and persistent exacerbations; 2) where there is diagnostic uncertainty or suspected comorbidity; 3) whenever they feel "out of their depth." Overall, the panel concurred that when used correctly, SITT has the potential to improve adherence, symptom control, and quality of life, and reduce exacerbations. Studies using real-world evidence need to confirm these benefits.
\end{abstract}

Keywords: maintenance therapy, routine care, treatment step-up, inhalers, guidelines

\section{Introduction}

According to the British Lung Foundation, 1.2 million people have been diagnosed with COPD in the UK. ${ }^{1}$ The intangible costs arising from excess mortality and reduced health-related quality of life (HRQoL) in people with COPD far exceed the direct costs to health services and indirect costs associated with, for example, lost productivity. ${ }^{2}$

Despite a decrease in the number of people who smoke, COPD represented $5.3 \%$ of the total mortality in the UK in 2012. ${ }^{1}$ Age- and sex-specific mortality from COPD has declined in recent years. ${ }^{3}$ However, other causes of mortality have shown a greater decline. ${ }^{3}$ Moreover, COPD is predominately a disease of older people. ${ }^{4}$ Partly driven by demographic changes, COPD mortality is rising. ${ }^{3}$ 
COPD is characterized by a progressive deterioration in lung function over many years, punctuated by periodic exacerbations, ${ }^{5}$ which drive much of the morbidity and mortality associated with COPD. For example, the risk of myocardial infarction was 2.27-fold higher 1-5 days after a COPD exacerbation and the risk of stroke was 1.26-fold higher between 1 and 49 days later. ${ }^{6}$ Moreover, exacerbations account for about $25 \%$ of the decline in lung function, increase the risk of mortality and hospital admissions, and reduce HRQoL in people with COPD. ${ }^{5,7-9}$ Daily mortality, for instance, peaks at 40 per 10,000 of the population in the first week after admission for a severe exacerbation. ${ }^{5}$ Mortality appears to be up to five times higher after the 10th severe exacerbation compared with that following the first hospitalization for COPD. ${ }^{\text {? }}$

\section{The growing choice of inhaled treatments for COPD}

The growing choice of drugs for COPD delivered using a variety of inhalers allows health care professionals (HCPs) to individualize treatment. The increasing number of drugs, combinations, and devices can, however, lead to confusion among HCPs. ${ }^{10}$

Many patients can be adequately treated with long-acting bronchodilator monotherapy with either a long-acting beta ${ }_{2}-$ agonist (LABA) or a long-acting muscarinic antagonist (LAMA). Other patients may require a double combination inhaler containing an inhaled corticosteroid (ICS) and a LABA (ICS plus LABA) or two long-acting bronchodilators (LAMA plus LABA). A proportion of patients escalate to "triple therapy" (ICS plus LABA plus LAMA) due to the clinical need to prevent further exacerbations, alleviate symptoms, or both despite using monotherapy or a double combination inhaler (Figure 1).

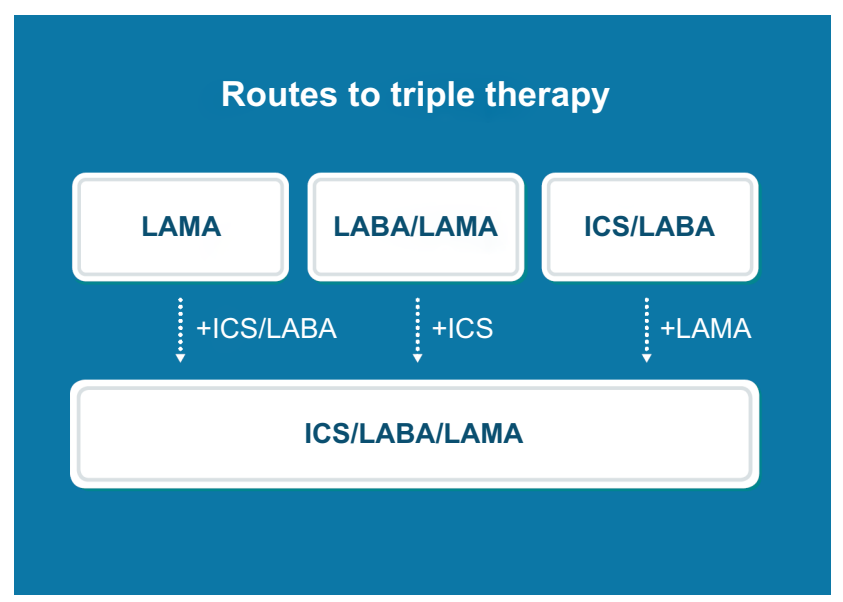

Figure I Routes to the instigation of triple therapy in patients with COPD. Abbreviations: LABA, long-acting beta ${ }_{2}$-agonist; LAMA, long-acting muscarinic antagonist; ICS, inhaled corticosteroid.
Historically, triple therapy has been prescribed with two separate inhalers, namely an ICS plus LABA inhaler and a LAMA inhaler. Two single-inhaler triple therapy (SITT) devices are now available in the UK: Trimbow (extra-fine formulation of beclometasone dipropionate plus formoterol fumarate dihydrate plus glycopyrronium [BDP/FF/G]) and Trelegy Ellipta (fluticasone furoate plus vilanterol trifenatate plus umeclidinium bromide $[\mathrm{FFu} / \mathrm{VI} / \mathrm{UM}])$. Trimbow is delivered from a pressurized metered dose inhaler (pMDI). ${ }^{11}$ Trelegy Ellipta uses a dry powder inhaler (DPI). ${ }^{12}$ Both are indicated for maintenance treatment of moderate-to-severe COPD in adults who are not adequately treated with a combination of an ICS and a LABA. ${ }^{11,12}$

SITT devices could help address poor adherence with COPD medications, which is common and may result in increased exacerbations, persistent symptoms, and poor economic outcomes. ${ }^{13,14}$ For example, a UK study performed before the introduction of SITT studied 2,801 COPD patients; only $45.6 \%$ of patients showed adequate adherence over 1 year, defined as a medication possession ratio (MPR) of $80 \%-120 \%$. The median time to discontinuation was 116 days. ${ }^{13}$ More recently, a German study reported nonadherence rates (MPR <80\%) after 12 months of $28.2 \%$ with LABA, $16.2 \%$ with LAMA, $43.8 \%$ with ICS, and $42.8 \%$ with inhalers combining ICS and LABA. ${ }^{15}$

Numerous factors contribute to poor adherence among COPD patients, including treatment complexity, such as dosing frequency, the number of medications, and ease of use of the inhalers. ${ }^{16,17}$ Sanduzzi et al reported that the proportion of patients with COPD who were compliant with treatment declined from $43 \%$ with once-daily treatment to $23 \%$ with therapy taken four times a day. ${ }^{17}$ In addition, many patients with COPD have comorbidities, receive polypharmacy, ${ }^{18}$ or have cognitive problems (especially the elderly), ${ }^{19}$ which can add to the complexity of treatment.

Furthermore, having to learn different techniques for different inhalers may undermine adherence: many patients fail to use even one inhaler correctly. A meta-analysis of 144 papers reported that only $31 \%$ (95\% CI $28 \%-35 \%$ ) of patients showed the correct technique with pMDIs and DPIs. A further $41 \%(36 \%-47 \%)$ of patients showed only "acceptable" inhaler technique. ${ }^{20}$ Using inhalers incorrectly undermines efficacy and adherence. ${ }^{17}$

\section{SITT and exacerbations}

Triple therapy with ICS plus LABA plus LAMA is now a mainstay of management for some patients with COPD. ${ }^{21-25}$ Patients who require further treatment for exacerbations, who experience symptoms, or both despite treatment with a 
Table I Summary of results of published clinical trials assessing single-inhaler triple therapy on exacerbation rate

\begin{tabular}{|c|c|c|c|c|}
\hline Study & $\mathbf{N}$ & Treatment & $\begin{array}{l}\text { Moderate-to-severe } \\
\text { annual exacerbation rate }\end{array}$ & $\begin{array}{l}\text { AE rate, \% (severel } \\
\text { serious } A E)\end{array}$ \\
\hline \multirow[t]{2}{*}{ FULFIL 25} & \multirow[t]{2}{*}{1,810} & Budesonide $(400 \mu \mathrm{g})$ plus FF (I2 $\mu \mathrm{g})$ twice daily & $\begin{array}{l}0.34 \text { at } 24 \text { weeks } \\
0.36 \text { at } 52 \text { weeks }\end{array}$ & $37.7(5.7)$ \\
\hline & & $\begin{array}{l}\text { Single-inhaler triple therapy (FFu I00 } \mu \text { g; UM } 62.5 \mu \mathrm{g} \text {; VI } 25 \mu \mathrm{g} \text { ) } \\
\text { once daily }\end{array}$ & $\begin{array}{l}0.22 \text { at } 24 \text { weeks } \\
0.20 \text { at } 52 \text { weeks }\end{array}$ & $38.9(5.4)$ \\
\hline \multirow[t]{3}{*}{ IMPACT $^{28}$} & \multirow[t]{3}{*}{10,355} & Single-inhaler dual therapy (FFu I00 $\mu$ g; VI $25 \mu \mathrm{g}$ ) once daily & 1.07 & $68(21)$ \\
\hline & & Single-inhaler dual therapy (VI $25 \mu \mathrm{g}$; UM $62.5 \mu \mathrm{g}$ ) once daily & 1.21 & $69(23)$ \\
\hline & & $\begin{array}{l}\text { Single-inhaler triple therapy (FFu I00 } \mu \mathrm{g} \text {; VI } 25 \mu \mathrm{g} \text {; UM } 62.5 \mu \mathrm{g} \text { ) } \\
\text { once daily }\end{array}$ & 0.91 & $70(22)$ \\
\hline \multirow[t]{2}{*}{ TRIBUTEE } & \multirow[t]{2}{*}{ ।,532 } & $\begin{array}{l}\text { Single-inhaler dual therapy (indacaterol } 85 \mu \mathrm{g} \text {; G } 43 \mu \mathrm{g} \text { ) } \\
\text { one actuation once daily }\end{array}$ & 0.59 & $67(17)$ \\
\hline & & $\begin{array}{l}\text { Single-inhaler triple therapy (BDP } 87 \mu \mathrm{g} \text {; FF } 5 \mu \mathrm{g} \text {; G } 9 \mu \mathrm{g} \text { ) } \\
\text { two actuations twice daily }\end{array}$ & 0.50 & $64(15)$ \\
\hline \multirow[t]{2}{*}{ TRILOGY23 } & \multirow[t]{2}{*}{$\mathrm{I}, 368$} & BDP $(100 \mu g)$ plus FF $(6 \mu g)$ two actuations twice daily & 0.53 & $56(18)$ \\
\hline & & $\begin{array}{l}\text { Single-inhaler triple therapy (BDP } 87 \mu \mathrm{g} \text {; FF } 5 \mu \mathrm{g} \text {; G } 9 \mu \mathrm{g} \text { ) } \\
\text { two actuations twice daily }\end{array}$ & 0.41 & $54(15)$ \\
\hline \multirow[t]{3}{*}{ TRINITY24 } & \multirow[t]{3}{*}{2,691} & Tiotropium ( $18 \mu \mathrm{g})$ one inhalation once daily & 0.57 & $58(15)$ \\
\hline & & $\begin{array}{l}\text { Single-inhaler triple therapy (BDP } 87 \mu \text {; FF } 5 \mu \text {; } \text { G } 9 \mu \mathrm{g} \text { ) } \\
\text { two actuations twice daily }\end{array}$ & 0.46 & $55(13)$ \\
\hline & & $\begin{array}{l}\text { Open-triple therapy (BDP } 100 \mu \mathrm{g} \text {; FF } 6 \mu \mathrm{g} \text { ) two actuations } \\
\text { twice daily plus tiotropium }(18 \mu \mathrm{g}) \text { one inhalation once daily }\end{array}$ & 0.45 & $58(13)$ \\
\hline
\end{tabular}

Abbreviations: AE, adverse event; BDP, beclometasone dipropionate; FF, formoterol fumarate; FFu, fluticasone furoate; G, glycopyrronium; N, total number of patients; UM, umeclidinium bromide; VI, vilanterol trifenatate.

double combination inhaler (ICS/LABA or LAMA/LABA) are often escalated to triple therapy (Figure 1). While escalation from LAMA or ICS/LABA was historically a common escalation pathway, escalation from LABA/LAMA is now becoming increasingly frequent. A study of 3,199 patients with COPD in UK primary care reported that $46 \%$ of those taking LAMA or LABA and 39\% of those taking ICS combinations progressed to triple therapy within 2 years of the start of treatment. ${ }^{26}$ It is unclear, however, if progression was appropriate in all of these cases and how many patients did not receive triple therapy if clinically indicated.

A growing body of evidence from randomized controlled clinical trials demonstrates that SITT reduces the risk of exacerbations (Table 1), is well tolerated, and alleviates symptoms. Several clinical trials of 1 year duration evaluating the effects of SITT have been conducted in symptomatic patients with forced expiratory volume in one second $\left(\mathrm{FEV}_{1}\right) \leq 50 \%$ of predicted and one or more exacerbations in the previous year.

The TRILOGY study compared BDP/FF/G with BDP/FF (Table 1). Triple therapy reduced the adjusted annual rate of moderate-to-severe exacerbations by $23 \%(P=0.005)$. $\mathrm{FEV}_{1}$ and patient-reported outcomes, notably HRQoL, improved significantly with $\mathrm{BDP} / \mathrm{FF} / \mathrm{G} .^{23}$

The TRINITY study showed that BDP/FF/G (Table 1) significantly reduced the rate of moderate and severe exacerbations (defined in Table 2$)$ by $20 \%(P=0.0025)$ and the rate of severe exacerbations by $32 \%(P=0.0174)$ compared to tiotropium monotherapy. Similar effects were observed with BDP/FF/G and open-triple therapy (Table 1), which required patients to use two inhalers. ${ }^{24}$

The TRIBUTE study reported that BDP/FF/G significantly reduced the rate of moderate-to-severe exacerbations compared with single-inhaler dual therapy (indacaterol plus glycopyrronium bromide) by $15 \%(P=0.043)$ in patients with severe or very severe airflow limitation. TRIBUTE provides evidence that supports the Global Initiative for Chronic Obstructive Lung Disease (GOLD) recommendation to escalate from LABA plus LAMA to triple therapy. ${ }^{21,27}$

The FULFIL study compared SITT (FFu/VI/UM) with ICS plus LABA combination therapy (budesonide and formoterol). Triple therapy was associated with significant

Table 2 Definition of exacerbation severity

\begin{tabular}{|l|l|}
\hline Severity & Definition \\
\hline Mild & $\begin{array}{l}\text { Increase in respiratory symptoms that can be } \\
\text { controlled with an increase in usual medication }\end{array}$ \\
\hline Moderate & $\begin{array}{l}\text { Requires treatment with systemic corticosteroids } \\
\text { or antibiotics or both }\end{array}$ \\
\hline Severe & Requires hospitalization or results in death \\
\hline
\end{tabular}

Notes: Data from European Medicines Agency. ${ }^{61}$ 
reductions in the annual exacerbation rate by $35 \%(P=0.002)$ and $44 \%(P=0.006)$ up to 24 and 52 weeks, respectively. The inclusion criteria for this study, unlike the BDP/FF/G studies, allowed low-risk patients without a history of exacerbations to be included. As a result, the overall exacerbation rates were lower compared to the $\mathrm{BDP} / \mathrm{FF} / \mathrm{G}$ trials (Table 1). ${ }^{25}$

The IMPACT study compared SITT (FFu/VI/UM) against single-inhaler dual therapy with either $\mathrm{FFu} / \mathrm{VI}$ or VI/UM. Triple therapy resulted in a significantly lower rate of moderate or severe COPD exacerbations, by $15 \%$ compared to $\mathrm{FFu} / \mathrm{VI}$ and by $25 \%$ compared to $\mathrm{VI} / \mathrm{UM}$ (both $P<0.001)$. SITT also reduced the risk of severe exacerbations that required hospitalization by $34 \%$ compared to $\mathrm{VI} / \mathrm{UM}$ ( 0.13 and 0.19 per year, respectively; $P<0.001) .{ }^{28}$

\section{Adverse events and external validity}

Most adverse events reported in these studies were mild to moderate. An increased rate of pneumonia has been associated with ICS use. In TRINITY, pneumonia occurred in $2.6 \%$ of the SITT arm, $2.2 \%$ of the open-triple therapy arm, and in $1.8 \%$ of those taking tiotropium monotherapy. ${ }^{24}$ These excess pneumonia rates with ICS are low compared to the benefit in terms of exacerbation prevention.

In TRIBUTE, pneumonia rates were similar with BDP/ $\mathrm{FF} / \mathrm{G}(3.7 \%)$ and indacaterol plus glycopyrronium bromide $(3.5 \%) .{ }^{27}$ In IMPACT, pneumonia as a serious adverse event occurred in $4 \%$ of patients receiving triple therapy or $\mathrm{FFu} / \mathrm{VI}$ and $3 \%$ of those receiving VI/UM. Based on the time-tofirst-event, there was a significantly higher risk of cliniciandiagnosed pneumonia with triple therapy than with VI/UM (HR $1.53 ; P<0.001) .{ }^{28}$ The risk of pneumonia appears to be greater in individuals who are older, or have lower $\mathrm{FEV}_{1}$, or have a previous history of pneumonia, ${ }^{21,29}$ which could explain why the increased pneumonia rate is not seen in all ICS studies, including TRIBUTE and SUMMIT. ${ }^{27,30}$

The inclusion and exclusion criteria of randomized clinical trials mean that the generalizability to real-life clinical practice may be unclear. For example, TRINITY and TRILOGY enrolled patients with COPD with postbronchodilator $\mathrm{FEV}_{1}$ of $\leq 50 \%$ and a history of at least one exacerbation in the previous 12 months. ${ }^{23,24}$ Patients with $\mathrm{FEV}_{1}>50 \%$ were not studied; extrapolation of the clinical trial results to this population is logical, but unproven.

Moreover, between $12.1 \%$ and $55.2 \%$ of patients with COPD have asthma-COPD overlap. ${ }^{31}$ Differentiating COPD and asthma can prove to be difficult in clinical practice. ${ }^{32}$ However, TRINITY and TRILOGY excluded patients with a history of being diagnosed with asthma, allergic rhinitis, or atopy. ${ }^{23,24}$ Such limitations may mean that the results are difficult to extrapolate to patients with ambiguous airway disease. Further randomized controlled trials, real-world evidence studies, and audits are needed to confirm these findings in less-selected COPD populations. Other trials assessing SITT including IMPACT are likely to be informative. ${ }^{33,34}$

\section{The need for a practical approach for primary care HCPs}

The GOLD management strategy ${ }^{21}$ and National Institute for Health and Care Excellence (NICE) guidlelines ${ }^{22}$ indicate the role of triple therapy in COPD management. However, SITT was not available when these documents were developed. Moreover, NICE suggests a sequence of inhaled therapies based on $\mathrm{FEV}_{1}{ }^{22}$ rather than exacerbations, which, as mentioned above, drive much of the morbidity and mortality associated with COPD. ${ }^{5,7,8}$

NICE suggests that HCPs should consider triple therapy for patients with persistent breathlessness and exacerbations. GOLD indicates triple therapy for group D (patients with a high symptom burden and high risk of exacerbation) as an escalation step after either LABA plus LAMA or ICS plus LABA. ${ }^{21}$ The GOLD ABCD algorithm is appropriate for initiating pharmacological treatment at diagnosis. During follow-up, a more individualized approach that considers the response to initial therapy and the clinical trajectory has been proposed to inform on treatment decisions, which should focus on two "treatable traits:" exacerbations and COPD symptoms. ${ }^{35}$

However, inappropriate triple therapy prescribing can occur, with some patients receiving ICS inappropriately. ${ }^{36}$ On the other hand, some patients do not receive ICS when clinically indicated. In part, this inappropriate prescribing may reflect confusion among HCPs given the various drugs, combinations, and devices. ${ }^{10}$ There is, therefore, a need to clarify the role of triple therapy in COPD management, especially to ensure that SITT is used appropriately.

This paper aims to meet this need and supplement, not replace, the GOLD management strategy ${ }^{21}$ and guidelines such as those published by NICE. ${ }^{22}$ It is not intended as a full systematic review. Rather, the paper offers practical, patient-focused advice aimed predominately at HCPs in primary care to optimize the use of SITT in COPD management. Prescribers may need to adapt suggestions as further studies are published.

\section{Process}

Chiesi commissioned a survey of HCPs in the UK performed by Opinion Health, a market research company. The survey 
aimed to identify issues around, and attitudes toward, SITT in COPD management. The results informed the development of practical, patient-focused suggestions by a multidisciplinary panel of experts in COPD management. An outline was developed following a meeting of the panel. This was developed into drafts and a final version with the input of the panel.

\section{HCP survey}

Opinion Health surveyed 200 general practitioners (GPs) and 100 nurse practitioners from a large panel of HCPs. An email sent to HCPs, who had previously subscribed to receive this kind of email, invited participants to click on a link and complete an online questionnaire, which Opinion Health estimated would take 10 minutes. Participants were profiled at recruitment to ensure a nationally representative spread in terms of sex, age, geographical region, and role. The risk of selection bias cannot, however, be eliminated and the extent to which these results apply to GPs and nurses more widely is unclear. Comprehensive quality checks ensured respondents completed the survey with due diligence. Market research was performed during August 2017, before the launch of Trimbow and Trelegy. The results reflect, therefore, expectations that HCPs had regarding SITT rather than being based on practical experience.

Overall, 89\% of HCPs prescribed COPD treatments. However, $33 \%$ of nurse practitioners did not prescribe treatment. Table 3 summarizes the main reasons for prescribing a triple therapy for COPD. Compared to the same time in the year before the survey, $36 \%$ and $17 \%$ of HCP respondents used more and less triple therapy, respectively. HCPs who responded to the survey cited "following guidelines" and reducing ICS prescription as common reasons for changes in the use of triple therapy compared to a year previously.

The survey found that HCPs reported feeling confident about when to prescribe free-triple therapy: 56\% and 37\% said they were of medium and high confidence, respectively, when judging if free-triple therapy is appropriate for their patients with COPD. Moreover, despite their lack of experience in prescribing SITT at the time the survey was carried out, $44.3 \%$ agreed or strongly agreed with the statement: "I feel comfortable in prescribing fixed-dose triple combination therapy administered using a single-inhaler to my COPD patients," while 37.2\% were neutral (neither agree nor disagree). However, $18.4 \%$ were not confident (disagreed or strongly disagreed).

Figure 2 shows the relative importance of factors that influence the choice of a pharmacological treatment for COPD. In descending order of importance, the five most
Table 3 Reasons for the changes in use of triple therapy

\begin{tabular}{|c|c|}
\hline Reason & $\begin{array}{l}\text { Respondents } \\
\text { citing, \% }\end{array}$ \\
\hline \multicolumn{2}{|l|}{ Lower use of triple therapy $(n=45)$} \\
\hline Less use of ICS & 49 \\
\hline Guidelines & 36 \\
\hline Evidence & 7 \\
\hline $\begin{array}{l}\text { Fewer patients eligible for single-inhaler } \\
\text { triple therapy }\end{array}$ & 4 \\
\hline Other & 4 \\
\hline \multicolumn{2}{|l|}{ Higher use of triple therapy $(n=95)$} \\
\hline Guidelines & 24 \\
\hline Increased awareness/education & 17 \\
\hline More choices available & 12 \\
\hline Better control of symptoms & 11 \\
\hline $\begin{array}{l}\text { More patients eligible for single-inhaler } \\
\text { triple therapy }{ }^{\mathrm{b}}\end{array}$ & 11 \\
\hline Evidence & 7 \\
\hline Effectiveness & 5 \\
\hline Other & 5 \\
\hline
\end{tabular}

Notes: 126 respondents reported no change in their use of triple therapy. Respondents could give one response to account for lower or higher use of triple therapy. aSurvey responses included: fewer patients on ICS, patients who changed from one general practice surgery to another, saw patients with less severe COPD. 'Respondents reported seeing more patients with COPD in general; therefore, the overall patient pool is larger.

Abbreviation: ICS, inhaled corticosteroid.

influential factors were: improvement in symptom control; ease of use; quality of life; frequency of exacerbations; and lung function. Indeed, 91\% of respondents ascribed high importance to improved symptom control when choosing a pharmacological treatment for COPD.

Table 4 summarizes opinions among HCPs about when they would prescribe SITT to a patient with COPD. Better patient compliance emerged as the main reason: 78\% of respondents either agreed or strongly agreed with this statement. Furthermore, $71 \%$ either agreed or strongly agreed that SITT should be used when a patient was hospitalized in the last year with a COPD exacerbation. Remaining breathless on current treatment (69\% either agreed or strongly agreed), experiencing an exacerbation on current treatment (62\%), and severe airflow limitation despite current treatment (61\%) were other reasons for prescribing a SITT. Nevertheless, 37\% of HCPs surveyed had a neutral position (neither agreed nor disagreed) about prescribing SITT to patients with COPD.

\section{A practical approach to patient- focused care}

The results of the survey highlight attitudes of HCPs in the UK toward COPD treatment and, in particular, the use 


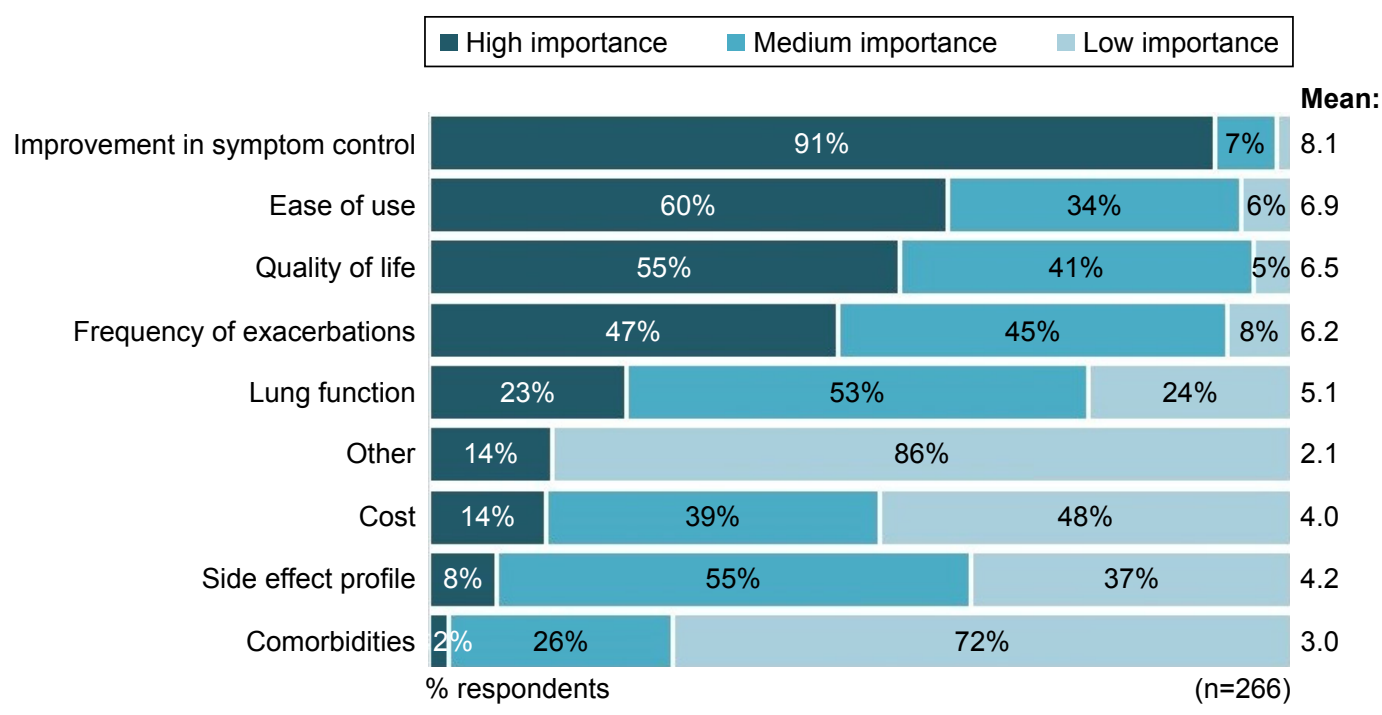

Figure 2 Factors that influence the choice of pharmacological treatment for COPD.

Notes: $\mathrm{n}=266$ except for "other" where $\mathrm{n}=7$. In your opinion, how important are the following factors in making a choice around which pharmacological COPD treatment should be prescribed? I denotes most important and 9 least important. Values for mean score: $I-3=$ high importance, 4-6= medium importance, 7-9= low importance.

of triple therapy. The key findings included the following points.

1. There is a trend toward more triple therapy being prescribed (36\%), while, at the same time, some HCPs are trying to reduce triple therapy use. On the one hand, the increase in prescriptions for triple therapy may reflect a previously unrecognized unmet need. On the other hand, the reduction in triple therapy use appears to reflect growing concerns about overprescribing of ICS, local guidance for stepping down, or both.

2. While $93 \%$ of HCPs expressed confidence in prescribing triple therapy, the level of confidence was lower when they were specifically asked about SITT.

3. Symptom control and ease of use were the two most common factors influencing choice of pharmacological treatment generally. When focusing on SITT, compliance and hospitalization were the most important influences.
These findings highlight the need to clarify the place of triple therapy in clinical practice and the potential role for SITT. The panel has, therefore, targeted this paper toward offering guidance in these areas.

Although the paper focuses on pharmacological treatment, appropriate non-pharmacological management is essential at every review and before prescribing triple therapy. HCPs should, therefore, consider factors that might contribute to symptom burden, exacerbations, or both with the current therapy (Table 5). In addition, HCPs should enquire about any risk factors, such as occupational exposure to vapor, gas, dust, and fumes, ${ }^{37,38}$ and pay particular attention to smoking status, offering advice and assistance to quit where indicated.

After addressing these factors, HCPs can consider escalation of treatment if required. Escalation to triple therapy commonly occurs from either LAMA monotherapy or a

Table 4 Health care professionals' opinions about when single-inhaler triple therapy should be prescribed to patients with COPD

\begin{tabular}{|l|l|l|l|l|}
\hline Statement & $\begin{array}{l}\text { Strongly } \\
\text { agree, } \%\end{array}$ & $\begin{array}{l}\text { Agree, } \\
\%\end{array}$ & $\begin{array}{l}\text { Neither agreel } \\
\text { disagree, } \%\end{array}$ & $\begin{array}{l}\text { Disagree/strongly } \\
\text { disagree, } \%\end{array}$ \\
\hline $\begin{array}{l}\text { Patient is not compliant with their current treatment due to } \\
\text { multiple inhaler use }(\mathrm{n}=300)\end{array}$ & 38 & 40 & 15 & 7 \\
\hline $\begin{array}{l}\text { Despite current treatment, patient has been hospitalized due to a } \\
\text { COPD exacerbation in the last year ( } \mathrm{n}=300)\end{array}$ & 21 & 50 & 23 & 6 \\
\hline Remains breathless on current treatment $(\mathrm{n}=300)$ & 15 & 54 & 22 & 9 \\
\hline Has had an exacerbation on current treatment $(\mathrm{n}=300)$ & 13 & 49 & 27 & $1 \mathrm{I}$ \\
\hline $\begin{array}{l}\text { Despite current treatment, has severe airflow limitation as } \\
\text { defined by spirometry ( } \mathrm{n}=300)\end{array}$ & 15 & 46 & 30 & 9 \\
\hline $\begin{array}{l}\text { Other }(\mathrm{n}=2 \mathrm{I}) \text { : respondents had the option to select "Other" and } \\
\text { input their own additional responses }\end{array}$ & 33 & 19 & 38 & 10 \\
\hline
\end{tabular}

Note: Respondents could give one response to each question. 
Table 5 Factors that health care professionals should check at every review and before changing treatment

\begin{tabular}{|l|}
\hline Exacerbation history \\
\hline Check compliance \\
\hline Check inhaler technique \\
\hline $\begin{array}{l}\text { Check smoking status and, if necessary, reiterate the need for } \\
\text { cessation }\end{array}$ \\
\hline Consider the possibility and potential impact of comorbidities \\
\hline Stress the importance of activity and exercise \\
\hline Check eligibility for and uptake of pulmonary rehabilitation \\
\hline Check that flu and other vaccinations are up to date \\
\hline
\end{tabular}

double combination treatment (LABA plus LAMA or ICS plus LABA). The introduction of dual bronchodilator treatments means that patients are now more likely to escalate from LAMA monotherapy to LABA plus LAMA before escalation to triple therapy. In general, clinicians will add a long-acting bronchodilator predominantly to alleviate symptoms, ${ }^{39-41}$ although there is an effect on exacerbations, ${ }^{42}$ or add an ICS to reduce the risk of exacerbations (Figure 1). ${ }^{43}$ According to the licenses and the GOLD management strategy, escalating to triple therapy does not depend on lung function. ${ }^{11,12,21}$

The exacerbation frequency (while on single or double maintenance treatment) that should be used as a trigger to escalate to triple therapy remains a subject of debate. The ECLIPSE study reported that patients with COPD with one exacerbation in the previous year are about twice as likely to experience an exacerbation during the year-long follow-up than patients with no previous exacerbations (OR 2.24; $P<0.001$ ), while this risk was further increased in patients with COPD with two or more exacerbations in the previous year (OR 5.72; $P<0.001) .{ }^{44}$ Similar findings have been reported in other large cohort studies. ${ }^{45}$

GOLD has set a threshold of two or more exacerbations or one hospitalization in the previous year to define high-risk individuals. ${ }^{21}$ It is important to note that this GOLD definition applies to newly diagnosed patients with COPD who are not taking maintenance treatment(s). ${ }^{21,35}$ The number of exacerbations that should be used to define high-risk patients who are already receiving maintenance treatment is less clear. ECLIPSE and other cohort studies have shown clearly an increased risk in patients with one exacerbation in the last year while taking various maintenance treatments, ${ }^{45,46}$ and the SITT studies have shown a significant effect on exacerbations using an entry criteria of one or more exacerbations in the last year. ${ }^{23-25,27}$ On the other hand, cohort studies have shown that many individuals with one exacerbation in the previous year do not experience an event in the subsequent year. ${ }^{46}$
Taking all these factors into account, the panel made suggestions based on their clinical experience and the evidence that one exacerbation in the last year increases the prospective exacerbation risk (although two or more exacerbations is a much stronger predictor of prospective risk). ${ }^{45,46}$ The panel proposed a practical approach to the problematic issue of whether to use one or two exacerbations in the last year as a threshold to guide escalation to triple therapy from monotherapy or double combination by using any one of the following criteria:

1. At least two exacerbations treated with oral corticosteroids, antibiotics, or both in the previous year;

2. At least one severe exacerbation that required hospital admission in the previous year;

3. One exacerbation a year on a repeated basis for 2 consecutive years. ${ }^{47}$

\section{Blood eosinophil counts: use in clinical practice}

The perception of HCPs toward blood eosinophil biomarker measurements was not assessed in the market research. However, the panel felt it important to include this hotly debated area, especially as blood eosinophil counts are now being used in clinical practice by some HCPs.

Post-hoc analyses of randomized clinical trials have demonstrated the ability of blood eosinophil counts to predict the effects of ICS on reducing exacerbation rates. For example, a post-hoc analysis $(n=4,528)$ of clinical trials that compared ICS/LABA with LABA showed a significant ICS effect at $>100$ cells $/ \mu \mathrm{L} .{ }^{48}$ Other post-hoc analyses ${ }^{49,50}$ of ICS/ LABA vs LABA/LAMA have reported similar findings of a relationship between higher blood eosinophil counts and exacerbation reduction: an $\sim 50 \%$ reduction in exacerbation frequency has been reported at $>300$ cells $/ \mu L{ }^{51,52}$ The ability of blood eosinophils to predict ICS effects has been confirmed in the SITT studies. ${ }^{24,27,28}$

The WISDOM ${ }^{51,52}$ and SUNSET ${ }^{53}$ studies examined ICS withdrawal from triple therapy. The WISDOM study enrolled patients on a variety of maintenance treatments, with only $39 \%$ taking triple therapy before the study. Patients in the SUNSET study were all taking triple therapy before enrollment. The exacerbation risk differed: WISDOM patients all had one or more exacerbations in the previous year, while SUNSET patients had no or one exacerbation in the previous year. Despite these differences in study design, both studies showed increased exacerbations in patients with $>300$ eosinophils $/ \mu \mathrm{L} .^{51-53}$ There is currently no international document defining eosinophil cutoff values for use in the clinic. Nevertheless, evidence 


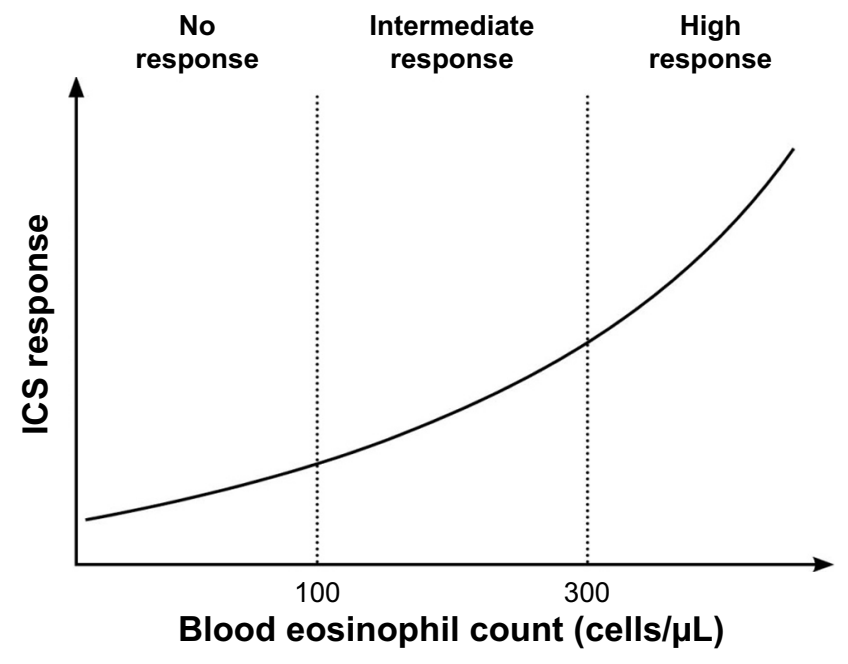

Figure 3 Higher blood eosinophil counts predict a better response to ICS. Abbreviation: ICS, inhaled corticosteroid.

indicates that $<100$ cells $/ \mu \mathrm{L}$ predicts no ICS response, while $>300$ cells $/ \mu \mathrm{L}$ predicts a relatively high ICS response (Figure 3).

\section{SITT}

Poor inhaler technique is common among COPD patients. ${ }^{54,55}$ The availability of two SITT devices (Trimbow and Trelegy Ellipta) provides an opportunity to simplify treatment for patients, as they may be using different inhaler devices to receive triple therapy. A recent study reported that singleinhaler $\mathrm{FFu} / \mathrm{VI} / \mathrm{UM}$ was non-inferior to $\mathrm{FFu} / \mathrm{VI}$ and $\mathrm{UM}$ as two inhalers based on the change from baseline in trough $\mathrm{FEV}_{1}$ at week 24 in patients with advanced COPD. Efficacy, HRQoL, and safety were similar in the two arms. ${ }^{56}$ In the panel's clinical experience, however, patients find using a single-inhaler more convenient than needing two or more devices. In patients suspected of poor adherence, a switch from two or three inhalers to a single device may improve COPD control. Simplifying treatment may improve adherence, although this has not been evaluated formally with SITT for COPD.

In addition to the number of inhalers, HCPs need to consider the ease of use of any device prescribed. Ease of use is an influential factor that determines adherence. ${ }^{16,17}$ Poor inhaler technique might contribute to symptoms and exacerbations, and HCPs should ensure that patients are able to use any device prescribed.

Trimbow is delivered from an pMDI, ${ }^{11}$ whereas Trelegy Ellipta uses a proprietary DPI. ${ }^{12}$ The panel concurred that reducing the number of inhalers and using devices with the same inspiratory flow requirement mean that patients only need to learn one inhaler technique. The slow and steady inspiratory flow required for an pMDI may also mirror the breathing pattern of patients with COPD.

To avoid the risk of confusion, especially with respect to inhaler technique, drugs should be prescribed by brand and not generically. The market research conducted to inform this paper found that $58 \%$ of HCPs who responded prescribed generic inhalers, which underscores the importance of reinforcing appropriate prescribing practice.

\section{Review treatment after an exacerbation or if patients remain symptomatic}

HCPs should be aware that COPD clinical phenotype (disease attributes such as signs and symptoms) can alter over time, partly due to the inevitable deterioration in lung function as well as, in some patients, ongoing inflammation. For example, the risk of recurrence is highest in the 8 weeks after the initial COPD exacerbation, ${ }^{9}$ which reflects persistent inflammation. The variable clinical trajectory in patients with COPD underscores the importance of regular monitoring.

The panel agreed that HCPs should also consider referral to a specialist:

1. When there is limited response to treatment and persistent exacerbations;

2. Where there is diagnostic uncertainty or suspected comorbidity;

3. Whenever they feel "out of their depth."

Referral could be, depending on the clinical issue and the level of expertise of the HCP, secondary care, a GP with a special interest, or the practice's respiratory lead.

\section{Stepping down treatment}

During each review, the HCP should consider whether stepping down treatment is appropriate. A study from the UK that enrolled 3,199 patients with COPD found that of those taking triple therapy at baseline, $25 \%$ and $31 \%$ stepped down to LABA plus ICS or LAMA within 24 months. ${ }^{26}$ This may suggest overprescribing of triple therapy.

Stepping down treatment should be carefully managed. The group agreed that patients without any previous history of exacerbations should have the ICS component of triple therapy removed. Patients who have previously suffered with exacerbations, but now are stable on triple therapy present a more difficult issue. It is possible that some of these patients are overtreated and that they would be managed sufficiently on a LABA plus LAMA. Such decisions should be made on an individual basis after carefully considering fine details 
of the clinical history and using the blood eosinophil count (if the HCP feels confident using this biomarker). ${ }^{35}$ ICSs should be continued when the history suggests asthma overlaps with COPD. An individualized approach should consider if the ICS component confers benefit and/or contributes to side effects in patients who continue to exacerbate despite taking triple therapy. The blood eosinophil count can help predict clinical benefit in this situation.

\section{Counseling and educating patients}

Patients with COPD rely on their inhaled medication to control their symptoms and reduce the risk of exacerbations. So, not surprisingly, patients with COPD may find changes to their treatment disconcerting. Indeed, unless patients with COPD and, when appropriate, relatives and carers are trained, counseled, and educated, switching inhalers can reduce adherence and be associated with poor clinical outcomes and increased use of health care resources. ${ }^{57}$

Training, counseling, and education should be individualized to each patient. In the opinion of the panel, HCPs should typically reassure patients that SITT is not being suggested because of cost. The discussion should highlight symptomatic efficacy, reduction in exacerbations, and ease of use. In particular, discussing the efficacy data might help counter steroid phobia. In addition, the eosinophil count can help discussions with patients about whether ICSs are appropriate. Counseling and education should also include risks associated with ICS, notably pneumonia and mycobacterial infections. ${ }^{58-60}$

\section{Conclusion}

Despite recent advances in pharmacotherapy, COPD remains an important cause of death, disability, and health care expenditure. ${ }^{1-3}$ Triple therapy with ICS plus LABA plus LAMA is a mainstay of COPD management for some patients. ${ }^{21,23-25}$ However, adding new treatments can increase treatment complexity and, in turn, influence adherence. ${ }^{16,17}$ The availability of two SITT devices (Trimbow and Trelegy Ellipta) represents another advancement in the evolution of COPD therapy.

This paper offers practical, patient-focused advice aimed predominately at HCPs in primary care to optimize the use of SITT in patients with established COPD. ${ }^{21}$ Overall, the panel concurred that when used correctly, SITT has the potential to improve adherence and, in turn, improve symptom control and HRQoL, as well as reduce exacerbations. Studies using real-world evidence need to confirm these benefits.

\section{Acknowledgments}

Publication and preparation of this paper have been commissioned and funded by Chiesi Limited, which reviewed the manuscript for medical and scientific accuracy only. Chiesi Limited commissioned the survey of HCPs. Mark Greener, on behalf of M\&F Health, provided medical writing services funded by Chiesi Limited. M\&F Health provided logistical support, funded by Chiesi Limited.

\section{Disclosure}

Dr S Gaduzo reports receiving consultancy fees for speaking at and chairing educational meetings and conferences on behalf of AstraZeneca, Boehringer Ingelheim, Chiesi Limited, GlaxoSmithKline, Pfizer, and Novartis. Dr V McGovern reports accepting speaker fees, advisory panel fees, and conference sponsorship from the following pharmaceutical companies: Altana, AstraZeneca, Almirall, Boehringer Ingelheim, Chiesi, GlaxoSmithKline, Merck Sharp \& Dohme, NAPP, Novartis, Orion Pharma, and Pfizer. J Roberts reports receiving consultancy fees from AstraZeneca, Chiesi Limited, and GlaxoSmithKline. JE Scullion reports accepting honoraria or support from ADMIT, AstraZeneca, Boehringer Ingelheim, Mundipharma, Mylan, NAPP, Nutricia, Orion Pharma, Roche, Teva, Trudell Medical, and UKIG. Professor D Singh reports receiving sponsorship to attend and speak at international meetings, honoraria for lecturing or attending advisory boards, and research grants from AstraZeneca, Boehringer Ingelheim, Chiesi Limited, Genentech, GlaxoSmithKline, Glenmark, Johnson \& Johnson, Merck, NAPP, Novartis, Pfizer, Skypharma, Takeda, Teva, Theravance, and Verona. The authors report no other conflicts of interest in this work.

\section{References}

1. British Lung Foundation. Chronic obstructive pulmonary disease (COPD) statistics. Available from: https://statistics.blf.org.uk/copd. Accessed December 2017. Accessed November 14, 2018.

2. British Lung Foundation. Estimating the economic burden of respiratory illness in the UK. 2017. Available from: https://cdn.shopify. com/s/files/1/0221/4446/files/PC-1601_-_Economic_burden_report FINAL_8cdaba2a-589a-4a49-bd14-f45d66167795.pdf. Accessed November 14, 2018.

3. Burney PGJ, Patel J, Newson R. Global and regional trends in chronic obstructive pulmonary disease mortality 1990-2010. Eur Respir J. 2015;45:1239-1247.

4. Haughney J, Gruffydd-Jones K, Roberts J, Lee AJ, Hardwell A, Mcgarvey L. The distribution of COPD in UK general practice using the new GOLD classification. Eur Respir J. 2014;43(4):993-1002.

5. Suissa S, Dell'Aniello S, Ernst P. Long-term natural history of chronic obstructive pulmonary disease: severe exacerbations and mortality. Thorax. 2012;67(11):957-963.

6. Donaldson GC, Hurst JR, Smith CJ, Hubbard RB, Wedzicha JA. Increased risk of myocardial infarction and stroke following exacerbation of COPD. Chest. 2010;137(5):1091-1097. 
7. Wedzicha JA, Singh R, Mackay AJ. Acute COPD exacerbations. Clin Chest Med. 2014;35(1):157-163.

8. Celli BR, Thomas NE, Anderson JA, et al. Effect of pharmacotherapy on rate of decline of lung function in chronic obstructive pulmonary disease: results from the TORCH study. Am J Respir Crit Care Med. 2008; 178(4):332-338.

9. Qureshi H, Sharafkhaneh A, Hanania NA. Chronic obstructive pulmonary disease exacerbations: latest evidence and clinical implications. Ther Adv Chronic Dis. 2014;5(5):212-227.

10. Centre for Reviews and Dissemination, University of York. Inhaler devices for the management of asthma and COPD. Effective Health Care. 2003;8(number 1):1-12. Available from: www.york.ac.uk/media/ crd/ehc81.pdf. Accessed November 14, 2018.

11. Chiesi Limited. Trimbow 87 micrograms $/ 5$ micrograms $/ 9$ micrograms pressurised inhalation, solution. Summary of product characteristics, 2017. Available from: https://www.medicines.org.uk/emc/ medicine/33828. Accessed November 14, 2018.

12. GlaxoSmithKline UK. Trelegy. Summary of product characteristics, 2018. Available from: https://www.medicines.org.uk/emc/ medicine/34357. Accessed November 14, 2018.

13. Covvey JR, Mullen AB, Ryan M. A comparison of medication adherence/persistence for asthma and chronic obstructive pulmonary disease in the United Kingdom. Int J Clin Pract. 2014;68: $1200-1208$.

14. van Boven JF, Chavannes NH, van der Molen T, Rutten-van Mölken MP, Postma MJ, Vegter S. Clinical and economic impact of non-adherence in COPD: a systematic review. Respir Med. 2014;108(1):103-113.

15. Mueller S, Wilke T, Bechtel B, Punekar YS, Mitzner K, Virchow JC. Non-persistence and non-adherence to long-acting COPD medication therapy: A retrospective cohort study based on a large German claims dataset. Respir Med. 2017;122:1-11.

16. Mäkelä MJ, Backer V, Hedegaard M. Adherence to inhaled therapies, health outcomes and costs in patients with asthma and COPD. Respir Med. 2013;107:1481-1490.

17. Sanduzzi A, Balbo P, Candoli P, et al. COPD: adherence to therapy. Multidiscip Respir Med. 2014;9(1):60.

18. Díez-Manglano J, Barquero-Romero J, Mena PA, et al. Polypharmacy in patients hospitalised for acute exacerbation of COPD. Eur Respir J. 2014;44(3):791-794.

19. Corsonello A, Scarlata S, Pedone C, et al. Treating COPD in older and oldest old patients. Curr Pharm Des. 2015;21(13):1672-1689.

20. Sanchis J, Gich I, Pedersen S. Systematic review of errors in inhaler use: has patient technique improved over time? Chest. 2016;150(2): 394-406.

21. Global Initiative for Chronic Obstructive Lung Disease (GOLD). Global strategy for the diagnosis, management and prevention of COPD. 2017. Available from: http://goldcopd.org/gold-2017-global-strategydiagnosis-management-prevention-copd. Accessed November 14, 2018.

22. National Institute for health and Care Excellence (NICE). Chronic obstructive pulmonary disease in over 16s: diagnosis and management. 2010. Available from: https://www.nice.org.uk/guidance/cg101. Accessed November 14, 2018.

23. Singh D, Papi A, Corradi M, et al. Single inhaler triple therapy versus inhaled corticosteroid plus long-acting $\beta 2$-agonist therapy for chronic obstructive pulmonary disease (TRILOGY): a double-blind, parallel group, randomised controlled trial. Lancet. 2016;388(10048):963-973.

24. Vestbo J, Papi A, Corradi M, et al. Single inhaler extrafine triple therapy versus long-acting muscarinic antagonist therapy for chronic obstructive pulmonary disease (TRINITY): a double-blind, parallel group, randomised controlled trial. Lancet. 2017;389(10082):1919-1929.

25. Lipson DA, Barnacle H, Birk R, et al. FULFIL Trial: once-daily triple therapy for patients with chronic obstructive pulmonary disease. Am J Respir Crit Care Med. 2017;196(4):438-446.

26. Wurst KE, Punekar YS, Shukla A. Treatment evolution after COPD diagnosis in the UK primary care setting. PLoS One. 2014;9(9): e105296.
27. Papi A, Vestbo J, Fabbri L, et al. Extrafine inhaled triple therapy versus dual bronchodilator therapy in chronic obstructive pulmonary disease (TRIBUTE): a double-blind, parallel group, randomised controlled trial. Lancet. 2018;391(10125):1076-1084.

28. Lipson DA, Barnhart F, Brealey N, et al. Once-daily single-inhaler triple versus dual therapy in patients with COPD. N Engl J Med. 2018; 378(18):1671-1680.

29. Crim C, Dransfield MT, Bourbeau J, et al. Pneumonia risk with inhaled fluticasone furoate and vilanterol compared with vilanterol alone in patients with COPD. Ann Am Thorac Soc. 2015;12(1):27-34.

30. Vestbo J, Anderson JA, Brook RD, et al. Fluticasone furoate and vilanterol and survival in chronic obstructive pulmonary disease with heightened cardiovascular risk (SUMMIT): a double-blind randomised controlled trial. Lancet. 2016;387(10030):1817-1826.

31. Wurst KE, Kelly-Reif K, Bushnell GA, Pascoe S, Barnes N. Understanding asthma-chronic obstructive pulmonary disease overlap syndrome. Respir Med. 2016;110:1-11.

32. Price D, West D, Brusselle G, et al. Management of COPD in the UK primary-care setting: an analysis of real-life prescribing patterns. Int J Chron Obstruct Pulmon Dis. 2014;9:889-905.

33. Pascoe SJ, Lipson DA, Locantore N, et al. A phase III randomised controlled trial of single-dose triple therapy in COPD: the IMPACT protocol. Eur Respir J. 2016;48(2):320-330.

34. GSK. GSK and Innoviva report positive headline results from IMPACT study showing single inhaler triple therapy Trelegy Ellipta reduced COPD exacerbations. Available from: https://www.gsk.com/en-gb/ media/press-releases/gsk-and-innoviva-report-positive-headlineresults-from-impact-study-showing-single-inhaler-triple-therapytrelegy-ellipta-reduced-copd-exacerbations. Accessed November 14, 2018.

35. Singh D, Barnes PJ, Stockley R, Lopez Valera MV, Vogelmeier C, Agusti A. Pharmacological treatment of COPD: the devil is always in the detail. Eur Respir J. 2018;51(4):1800263.

36. Brusselle G, Price D, Gruffydd-Jones K, et al. The inevitable drift to triple therapy in COPD: an analysis of prescribing pathways in the UK. Int J Chron Obstruct Pulmon Dis. 2015;10:2207-2217.

37. Kraïm-Leleu M, Lesage FX, Drame M, Lebargy F, Deschamps F. Occupational risk factors for COPD: A case-control study. PLoS One. 2016;11(8):e0158719.

38. Omland Ø, Würtz ET, Aasen TB, et al. Occupational chronic obstructive pulmonary disease: a systematic literature review. Scand $J$ Work Environ Health. 2014;40(1):19-35.

39. Singh D. New combination bronchodilators for chronic obstructive pulmonary disease: current evidence and future perspectives. Br J Clin Pharmacol. 2015;79(5):695-708.

40. Bateman ED, Chapman KR, Singh D, et al. Aclidinium bromide and formoterol fumarate as a fixed-dose combination in COPD: pooled analysis of symptoms and exacerbations from two six-month, multicentre, randomised studies (ACLIFORM and AUGMENT). Respir Res. 2015;16:92.

41. Singh D, Ferguson GT, Bolitschek J, et al. Tiotropium + olodaterol shows clinically meaningful improvements in quality of life. Respir Med. 2015;109(10):1312-1319.

42. Singh D, Roche N, Halpin D, Agusti A, Wedzicha JA, Martinez FJ. Current controversies in the pharmacological treatment of chronic obstructive pulmonary disease. Am J Respir Crit Care Med. 2016; 194(5):541-549.

43. Singh D, Corradi M, Spinola M, Petruzzelli S, Papi A. Extrafine beclometasone diproprionate/formoterol fumarate: a review of its effects in chronic obstructive pulmonary disease. NPJ Prim Care Respir Med. 2016;26:16030.

44. Hurst JR, Vestbo J, Anzueto A, et al. Susceptibility to exacerbation in chronic obstructive pulmonary disease. $N$ Engl J Med. 2010;363(12): 1128-1138.

45. Keene JD, Jacobson S, Kechris K, et al. Biomarkers predictive of exacerbations in the SPIROMICS and COPDGene cohorts. Am J Respir Crit Care Med. 2017;195(4):473-481. 
46. Hurst JR, Vestbo J, Anzueto A, et al. Susceptibility to exacerbation in chronic obstructive pulmonary disease. N Engl J Med. 2010;363(12): 1128-1138.

47. Mahboub BH, Vats MG, Al Zaabi A, et al. Joint statement for the diagnosis, management, and prevention of chronic obstructive pulmonary disease for Gulf Cooperation Council countries and Middle East-North Africa region, 2017. Int J Chron Obstruct Pulmon Dis. 2017;12: 2869-2890.

48. Bafadhel M, Peterson S, de Blas MA, et al. Predictors of exacerbation risk and response to budesonide in patients with chronic obstructive pulmonary disease: a post-hoc analysis of three randomised trials. Lancet Respir Med. 2018;6(2):117-126.

49. Siddiqui SH, Guasconi A, Vestbo J, et al. Blood eosinophils: a biomarker of response to extrafine beclomethasone/formoterol in chronic obstructive pulmonary disease. Am J Respir Crit Care Med. 2015;192(4): 523-525.

50. Pascoe S, Locantore N, Dransfield MT, Barnes NC, Pavord ID. Blood eosinophil counts, exacerbations, and response to the addition of inhaled fluticasone furoate to vilanterol in patients with chronic obstructive pulmonary disease: a secondary analysis of data from two parallel randomised controlled trials. Lancet Respir Med. 2015;3(6):435-442.

51. Calverley PMA, Tetzlaff K, Vogelmeier C, et al. Eosinophilia, frequent exacerbations, and steroid response in chronic obstructive pulmonary disease. Am J Respir Crit Care Med. 2017;196(9):1219-1221.

52. Watz H, Tetzlaff K, Wouters EF, et al. Blood eosinophil count and exacerbations in severe chronic obstructive pulmonary disease after withdrawal of inhaled corticosteroids: a post-hoc analysis of the WISDOM trial. Lancet Respir Med. 2016;4(5):390-398.

53. Chapman KR, Hurst JR, Frent SM, et al. Long-Term Triple Therapy De-escalation to Indacaterol/Glycopyrronium in Patients with Chronic Obstructive Pulmonary Disease (SUNSET): A Randomized, DoubleBlind, Triple-Dummy Clinical Trial. Am J Respir Crit Care Med. 2018; 198(3):329-339.
54. Chorão P, Pereira AM, Fonseca JA. Inhaler devices in asthma and COPD - an assessment of inhaler technique and patient preferences. Respir Med. 2014;108(7):968-975.

55. Pothirat C, Chaiwong W, Phetsuk N, Pisalthanapuna S, Chetsadaphan N, Choomuang W. Evaluating inhaler use technique in COPD patients. Int J Chron Obstruct Pulmon Dis. 2015;10:1291-1298.

56. Bremner PR, Birk R, Brealey N, Ismaila AS, Zhu CQ, Lipson DA. Single-inhaler fluticasone furoate/umeclidinium/vilanterol versus fluticasone furoate/vilanterol plus umeclidinium using two inhalers for chronic obstructive pulmonary disease: a randomized non-inferiority study. Respir Res. 2018;19(1):19.

57. Braido F, Lavorini F, Blasi F, Baiardini I, Canonica GW. Switching treatments in COPD: implications for costs and treatment adherence. Int J Chron Obstruct Pulmon Dis. 2015;10:2601-2608.

58. Brode SK, Campitelli MA, Kwong JC, et al. The risk of mycobacterial infections associated with inhaled corticosteroid use. Eur Respir J. 2017;50(3):1700037.

59. Festic E, Scanlon PD. Incident pneumonia and mortality in patients with chronic obstructive pulmonary disease. A double effect of inhaled corticosteroids? Am J Respir Crit Care Med. 2015;191(2):141-148.

60. Finney L, Berry M, Singanayagam A, Elkin SL, Johnston SL, Mallia P. Inhaled corticosteroids and pneumonia in chronic obstructive pulmonary disease. Lancet Respir Med. 2014;2(11):919-932.

61. European Medicines Agency. Guideline on clinical investigation of medicinal products in the treatment of chronic obstructive pulmonary disease (COPD). 2012. Available from: www.ema.europa.eu/docs/en GB/document_library/Scientific_guideline/2012/08/WC500130880. pdf. Accessed November 14, 2018.
International Journal of COPD

\section{Publish your work in this journal}

The International Journal of COPD is an international, peer-reviewed journal of therapeutics and pharmacology focusing on concise rapid reporting of clinical studies and reviews in COPD. Special focus is given to the pathophysiological processes underlying the disease, intervention programs, patient focused education, and self management protocols.

\section{Dovepress}

This journal is indexed on PubMed Central, MedLine and CAS. The manuscript management system is completely online and includes a very quick and fair peer-review system, which is all easy to use. Visit http://www.dovepress.com/testimonials.php to read real quotes from published authors. 